ACM International Conference Proceeding Series9 April 2018, Pages 81-872nd International Conference on Information System and Data Mining, ICISDM 2018; Florida Polytechnic UniversityLakeland; United States; 9 April 2018 through 11 April 2018; Code 137526

\title{
Designing a decision tree for cross-device communication technology aimed at iOS and android developers(Conference Paper)
}

- Chioino, J.Email Author,

- Contreras, I.Email Author,

- Barrientos, A.Email Author,

- Vives, L.Email Author

- Department of Software Engineering, School of Engineering, Universidad Peruana de Ciencias Aplicadas, Lima, Peru

\begin{abstract}
View references (21)
This analysis proposes a decision tree for selecting cross-device communication technologies for iOS and Android mobile devices. This tree accelerates the selection of cross-device technologies by taking into account known use cases of interaction. Five different communication technologies were tested (Real-time Multiplayer, Nearby Messages, PeerJS, iBeacon and Eddystone) by means of 13 proof of concept applications distributed between both operating systems (Android-iOS, iOS-iOS, Android-Android) and the design of 20 architecture diagrams of three types: sequence (connection to services and message sending), deployment and component. The decision tree was validated by mobile development experts resulting in a maximum reduction of up to 30 days of technology selection research. The effectiveness of the tree as a tool is $60 \%$, its usefulness $80 \%$ and its ease of comprehension $90 \%$, according to the results obtained from the experts. (C) 2018 Association for Computing Machinery.
\end{abstract}

\section{Author keywords}

AndroidBeaconsBluetooth low energyCross-deviceCross-platformHybrid appsIOSMobile developmentNative appsSoftware architecture

\section{Indexed keywords}

$\begin{array}{cl}\begin{array}{c}\text { Engineering } \\ \text { controlled terms: }\end{array} & \begin{array}{l}\text { Data miningDecision treesInformation systemsInformation } \\ \text { useiOS (operating system)Real time systemsSoftware } \\ \text { architecture }\end{array} \\ \begin{array}{c}\text { Engineering } \\ \text { uncontrolled terms }\end{array} & \begin{array}{c}\text { AndroidBeaconsBluetooth low energies (BTLE)Cross- } \\ \text { deviceCross-platformMobile development }\end{array} \\ \begin{array}{c}\text { Engineering main } \\ \text { heading: }\end{array} & \text { Android (operating system) }\end{array}$


- ISBN: 978-145036354-9

- Source Type: Conference Proceeding

- Original language: English

- DOI: $10.1145 / 3206098.3206103$

- Document Type: Conference Paper

- Sponsors:

- Publisher: Association for Computing Machinery 